\title{
Use of hydrogen as a source of clean energy
}

\author{
Danut Grecea*, Gabriela Pupazan, Marius Darie, Mihaela Paraian, and Cosmin Colda
}

National Institute for Research and Development in Mine Safety and Protection to Explosion INSEMEX, 32-34 G-ral Vasile Milea Street, Petrosani, Romania

\begin{abstract}
The increase in energy consumption is closely correlated with the continuous evolution of human society, which implies both the depletion of fossil fuels and the increase in pollution levels. One solution to these problems is to obtain electricity from renewable sources but also to use alternative fuels for car transportation. Within the paper, there are presented the necessary conditions for the design of hydrogen gas stations in accordance with the legal requirements in force regarding the protection to explosion.
\end{abstract}

\section{Introduction}

Renewable energy sources are highly valued at the moment and their efficiency has been recognized worldwide. To promote renewable energy sources, many states have developed and implemented policies and strategies that facilitate access to these sources in the electricity system and support investment in this area [1].

Renewable energy refers to the types of energy produced by the power transfer resulting from renewable natural processes. Renewable energy sources include: solar energy, wind energy, biomass energy, hydropower and geothermal energy. Thus, solar, wind, hydro, biomass and geothermal energy can be obtained using different methods.

Renewable energy is an alternative to fossil fuel energy for several reasons: it is inexhaustible, it has a minimal effect on the environment, it does not emit greenhouse gases and it does not produce waste, it allows a decentralized production of energy adopted to local needs and resources and it offers an important energy independence.

According to documents prepared by the European Union (EU), the integration of renewable energy sources in the electricity market is constantly growing, expected to become an important source of electricity by 2030 to cover electricity consumption by 2050 , which would lead to a reduction in $\mathrm{CO}_{2}$ emissions from burning fossil fuels and a reduction in the European Union's dependence on fossil fuel imports.

Energy consumption in the EU increased by $1 \%$ in 2018 compared to 2017, thus continuing to expand the goal of energy efficiency and set new targets for electricity consumption from primary sources for the coming years, Figure 1. Energy production from primary energy sources for 2018 is shown in Figure 2, where, for example, wind energy has a share of $11.7 \%$ of total energy for the EU, respectively $12.7 \%$ in Romania [2].

\footnotetext{
*Danut Grecea : danut.grecea@insemex.ro
} 


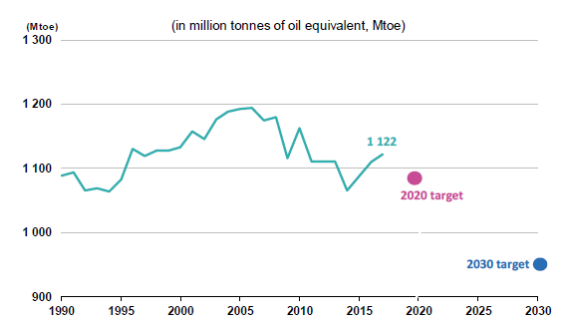

Fig. 1. Target for 2020 - 2030 in the EU for 2018 and energy consumption.

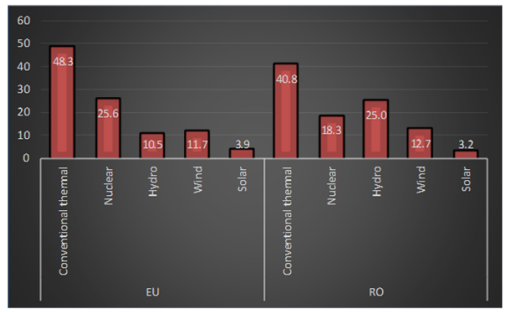

Fig. 2. Electricity production, EU and Romania by source, 2018 (in \%).

Another major objective is the use of alternative fuels for the transport system. One solution are hydrogen vehicles with zero emissions and can contribute to the decarbonization of the transport sector and limit the increase in global temperature. The electric vehicle with hydrogen fuel cells, as a passenger car, could gradually increase its share in the current national car park [3].

European Alternative Fuels Infrastructure Directorates establish a common framework for measures to implement alternative fuels infrastructure in the EU to minimize oil dependence and mitigate the environmental impact of transport and also set minimum requirements for the construction of alternative fuels infrastructure, including hydrogen fuel stations.

The major problem is the hydrogen supply network which is essential for the transport sector, which would allow operation. This infrastructure would work not only for cars, but also for buses or trucks on public roads, in addition it should be mentioned that it is necessary to refuel forklifts and other special vehicles for handling materials.

A hydrogen-powered vehicle is a vehicle that uses hydrogen, stored in the vehicle, as fuel for engines. Such vehicles convert the chemical energy of hydrogen to mechanical energy, either by burning hydrogen in an internal combustion engine or by reacting hydrogen with oxygen in a fuel cell to power electric motors.

\section{Hydrogen refuelling stations}

Hydrogen is a substance that comes in gaseous form at normal temperature and atmospheric pressure. In fact, hydrogen is found in solid form up to about $14 \mathrm{~K}\left(-259^{\circ} \mathrm{C}\right)$ when it passes into the liquid phase, and at about $20 \mathrm{~K}\left(-253^{\circ} \mathrm{C}\right)$ it vaporizes and passes into the gas phase.

The calorific value of hydrogen at atmospheric pressure and temperature is not a very advantageous element, being around $10\left(\mathrm{MJ} / \mathrm{Nm}^{3}\right)$ compared to natural gas for example; however, in the case of combustion processes carried out under pressure (gas turbines or internal combustion engines), where due to the pressure its density increases, hydrogen can be credited with about $120 \mathrm{MJ} / \mathrm{kg}$ compared to methane which has only $50 \mathrm{MJ} / \mathrm{kg}$ [4]. 
A hydrogen refuelling station, Figure 3, is a construction (infrastructure / installation) intended to supply a vehicle with hydrogen and is composed of a base unit, or a base unit and a production unit, if the hydrogen is a local product. The base unit comprises at least one high pressure storage system and one or more supply pumps or distributors.

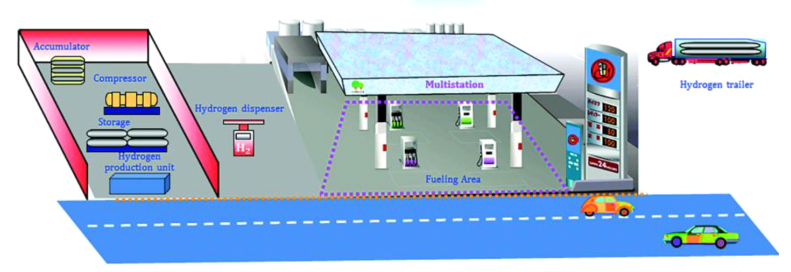

Fig. 3. Hydrogen refuelling station.

The hydrogen source for the refuelling station can be produced locally by a generating unit (micro-production) or can be delivered through pipelines, compressed hydrogen $\left(\mathrm{CGH}_{2}\right)$ or liquid hydrogen $\left(\mathrm{LH}_{2}\right)$. If it is delivered to the station at an intermediate pressure or liquid phase, and requires intermediate storage (hydrogen gas or liquid) a compression system is also required.

The components of the base unit of the hydrogen refuelling station are the following, Figure 4:

- Hydrogen storage tanks;

- Compressors;

- Pre-cooling system;

- Filling pump.

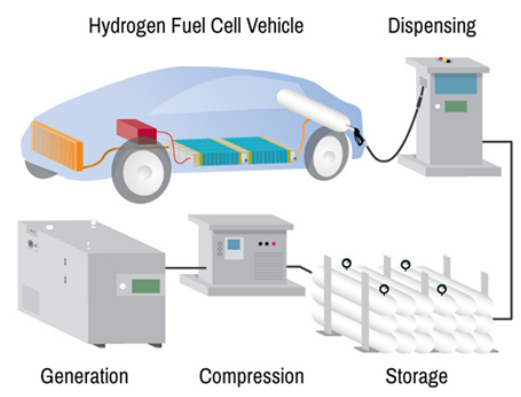

Fig. 4. Hydrogen station components.

In storage tanks, hydrogen is stored in low pressure tanks at 20-200 bar, medium and high-pressure tanks, with pressure levels of 200 - $450 \mathrm{bar}$, respectively 800 - $1000 \mathrm{bar}$;

Hydrogen from the low-pressure storage tank can be transferred through a compressor that can be classified: piston compressor, compressed air, diaphragm or ionic compressor and these are selected according to the design of the refuelling station (capacity used, consumption energy, profitability, etc.).

Hydrogen compression is a way to move from the pressure between storage (50 - 200 bar) to the loading (supply), max 1000 bar.

The supply protocol ensures that the hydrogen tank of a vehicle does not heat up to more than $85^{\circ} \mathrm{C}$ during a rapid refuelling.

Because hydrogen is compressed during fuelling, it heats up. For a refuelling at $700 \mathrm{bar}$, hydrogen is generally pre-cooled to $-40^{\circ} \mathrm{C}$. Higher pre-cooling temperatures are possible, but can lead to longer supply periods. 
The required low temperature is generated with the help of cooling equipment and a suitable heat exchanger.

The supply is carried out with the help of the distributor (supply pump) which includes: the supply nozzle, which delivers the compressed hydrogen in the vehicle's pressure tank (350 or 700 bar) and the user interface, which contains various displays indicating the pressure, filling level or measured quantity, Figure 5.

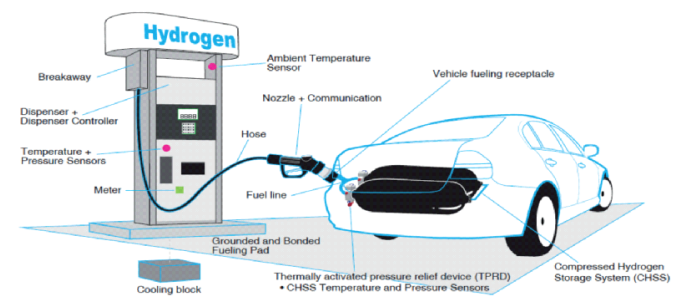

Fig. 5. Dispenser components.

In the case of a liquid hydrogen refuelling station (cryogenic - $\mathrm{LH}_{2}$ ), it is delivered and stored in a tank. If the fuel cell electric vehicle is supplied with hydrogen gas, the liquid hydrogen is transferred through a liquid pump to an evaporator, from where it can be introduced directly into the vehicle, without being cooled.

\section{Basic concepts for prevention and protection to explosion}

Explosion hazard may occur in all activities involving flammable substances in the form of gases, vapours, flammable mists or combustible dust which, when mixed with air, may form an explosive atmosphere [5-7].

As explosions can cause human and material losses, the assessment of the risk of explosion and the establishment of appropriate measures to reduce it to acceptable levels, in accordance with the regulations and standards in force, are of particular importance for the health and safety of people and property. The development of the types of protection was determined individually by critical situations, regarding the safety regime for the operation of the technical equipment in areas with explosive atmosphere, but also by the forecast of some imminent technical advances [6-8].

An essential element in assessing the risk of explosion in workplaces where explosive atmospheres may occur is represented by equipment that must be designed, manufactured, installed and maintained so that it cannot generate ignition sources.

Area classification is a method of analysing and classifying the environment in which explosive gaseous atmospheres can occur, so as to facilitate the correct choice and installation of electrical equipment that can be used safely in the given environment. The classification also takes into account the ignition characteristics of gases or vapours, such as ignition energy (gas group) and ignition temperature (temperature class).

After the area classification, a risk assessment may be performed to determine whether the consequences of igniting an explosive atmosphere require the use of equipment with a higher protection level (EPL) [7-12].

Explosion protection is designed to prevent ignition of explosive atmospheres, i.e., prevent potential ignition sources. With regard to the explosion hazard posed by the 
classification of the area, the technical equipment used in these areas must be eligible. This results in the categories and levels of protection of the equipment shown in Figure 6 [5-7].

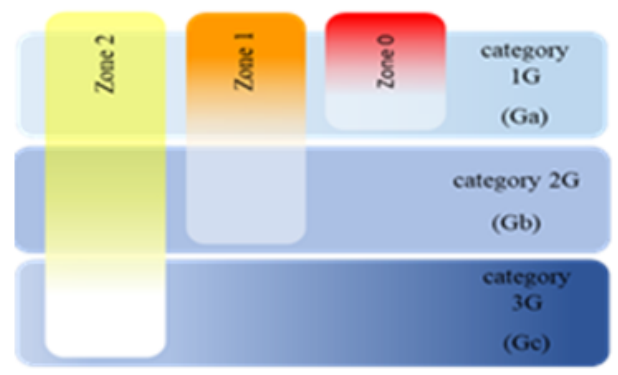

Fig. 6. Area correlation-protection category /level.

\section{Methodology for determining the hazardous areas extent}

In areas where hazardous amounts and concentrations of flammable gas or flammable vapours may occur, preventive measures must be applied to reduce the risk of explosion. The aim is to set out the essential criteria against which the risk of explosion can be assessed, and to make recommendations as to the design and control parameters that can be used to reduce this risk [5].

The extent of the hazardous zone or region where flammable gas may occur depends on the real ease rate and several other factors such as gas properties and release geometry and surrounding geometry. Figure 7 may be used as a guide to determine the extent of hazardous zones for various forms of release. Other forms of calculation or assessment based on reputable sources, e.g. Computational fluid dynamics (CFO) may also be applied [13].

The appropriate line should be selected based on the type of release as either: - an unimpeded jet release with high velocity;

- a diffusive jet release with low velocity or a jet that loses its momentum due to the geometry of the release or impingement on nearby surfaces;

- heavy gases or vapours that spread along horizontal surfaces (e.g., the ground).

This chart has been developed based on continuity equations and selected computational fluid dynamics (CFO) simulations assuming a dispersion distance proportional to the square root of the $\mathrm{X}$ axis and the results have been moderated for the purpose of [13].

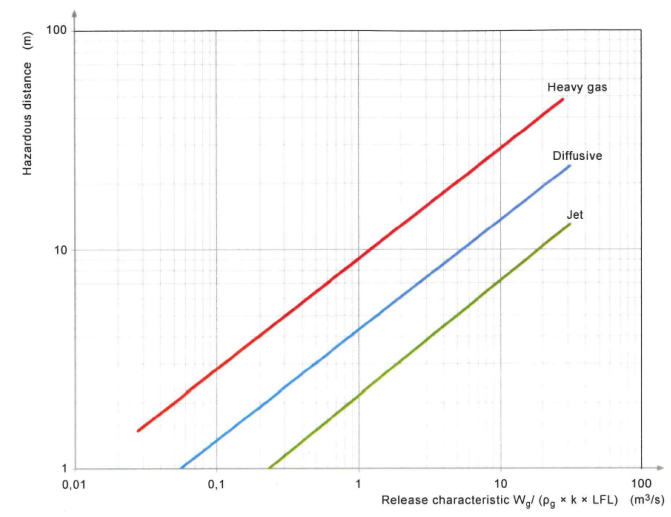

Fig. 7. Chart for estimating hazardous area distances. 
where: $W_{g} / \rho_{g} k L E F$ is a characteristic of release in $\left(\mathrm{m}^{3} / s\right) ; \rho_{g}=p_{a} M / R T_{a}$ is the density of the gas/vapour $\left(\mathrm{kg} / \mathrm{m}^{3}\right) ; k$ is the safety factor attributed to LFL, typically between 0.5 and 1.0.

Starting from the prescriptions of the SR EN 60079-10-1 standard, an application was made in EXCEL, which determines the potentially explosive area depending on the substance used, pressure, the area of accidental cracks that may occur and the results obtained are presented below.

The analysed substances, Table 1, are substances that can be used as alternative fuels for car transport.

Table 1. Characteristics of substances used to power cars.

\begin{tabular}{|c|c|c|c|c|c|c|}
\hline $\begin{array}{c}\text { Nr. } \\
\text { Crt. }\end{array}$ & Substance & LEL [\%] & $\begin{array}{c}\text { Air relative } \\
\text { density }\end{array}$ & $\begin{array}{c}\text { Sub- } \\
\text { group }\end{array}$ & $\begin{array}{c}\text { Temp. } \\
\text { class }\end{array}$ & $\begin{array}{c}\text { Molar } \\
\text { mass }\end{array}$ \\
\hline 1 & butane & 1.5 & 2.05 & IIA & $\mathrm{T} 2$ & 58 \\
\hline 2 & hydrogen & 4 & 0.07 & IIC & $\mathrm{T} 1$ & 2 \\
\hline 3 & methane & 4.4 & 0.55 & IIA & $\mathrm{T} 1$ & 16 \\
\hline 4 & propane & 2.1 & 1.56 & IIA & $\mathrm{T} 1$ & 44 \\
\hline
\end{tabular}

In the Excel application, the data necessary to determine the hazardous distance for a pipe on which the analysed substances are circulated at the pressures used to power the transport vehicles, in the hypothetical case of the appearance of a crack. The application analyses and determines sphere radius, in $[\mathrm{m}]$, of the dangerous area for different cracks areas. The Excel spreadsheet is shown in Figure 8 for determining radius of the dangerous atmosphere sphere for hydrogen, the crack area is $1 \mathrm{~mm}^{2}$ and the pressure of $700 \mathrm{bar}$.

\begin{tabular}{|c|c|c|c|c|}
\hline \multicolumn{5}{|c|}{ Estimation of extension a dangerous area } \\
\hline \multicolumn{5}{|c|}{$\begin{array}{l}\text { Objective: } \\
\end{array}$} \\
\hline \multicolumn{5}{|c|}{ hidrogen (LEL : 004 IIC T1) } \\
\hline Nr. No. & Name & Symbol & $\begin{array}{c}\text { Measure } \\
\text { unit }\end{array}$ & Value \\
\hline 1 & Safety coefficient & $\mathrm{f}$ & - & 5 \\
\hline 2 & Substance use & $\mathrm{cV}$ & $\mathrm{m}^{3} / \mathrm{min}$ & 0.5 \\
\hline 3 & $\begin{array}{l}\text { Concentration of hazardous volatiles in the } \\
\text { substance consumed }\end{array}$ & $\mathrm{Xx}$ & $\%$ & 60 \\
\hline 4 & Lower explosive limit & LEL & $\%$ & 4 \\
\hline 5 & Safety coefficient applied to the LEL & $\mathrm{k}$ & & 0.5 \\
\hline 6 & Ambient temperature & $\mathrm{t}$ & 'C & 10 \\
\hline 7 & Total ventilated volume & $v_{0}$ & $\mathrm{~m}^{3}$ & 100 \\
\hline 8 & Real volumetric air flow & dVtot & $\mathrm{m}^{3} / \mathrm{min}$ & 3 \\
\hline 9 & Maximum volumetric gas flow & (dG/dt)max & $\mathrm{m}^{3} / \mathrm{min}$ & 22.5326143 \\
\hline 10 & Absolute ambient temperature & $\mathrm{T}$ & $\mathrm{K}$ & 283 \\
\hline 11 & Minimum volumetric air flow & $(\mathrm{dV} / \mathrm{dt}) \mathrm{min}$ & $\mathrm{m}^{3} / \mathrm{min}$ & 10.88179155 \\
\hline 12 & Initial concentration of flammable material & $x_{0}$ & $\%$ & 100 \\
\hline 13 & Number of air changes per unit time & $\mathrm{C}$ & $1 / \mathrm{min}$ & 0.03 \\
\hline 14 & Calculated persistence period & $t_{x}$ & $\min$ & 652.00 \\
\hline 15 & Theoretical volume of explosive atmosphere & Vz & $\mathrm{m}^{3}$ & 1813.631925 \\
\hline 16 & Dangerous sphere radius & $\mathrm{r}$ & $\mathrm{m}$ & 12.009 \\
\hline
\end{tabular}

Fig. 8. Excel worksheet for hazardous area distances determination.

where the formulas used to calculate the parameters are: $(d G / d t) \max =c V^{*} X x / 100 ; T=t+273$; $(d V / d t) \min =d G /\left(k^{*} L E L\right) *(T T / 293) ; \quad C=d V t o t / V O ; \quad t x=(-f / C c) * L N(L E L * k / X O) ; \quad V z=$ $f^{*} d V / C c$ and $r=\left(3^{*} V z / P I()\right)^{\wedge}(1 / 3)$. 
The results are shown in Figure 9 where you can see the radius of the sphere, in $[\mathrm{m}]$, for propane and butane at the pressure of 20 bar are close increasing directly proportional to the area of the crack, in $\left[\mathrm{mm}^{2}\right]$.

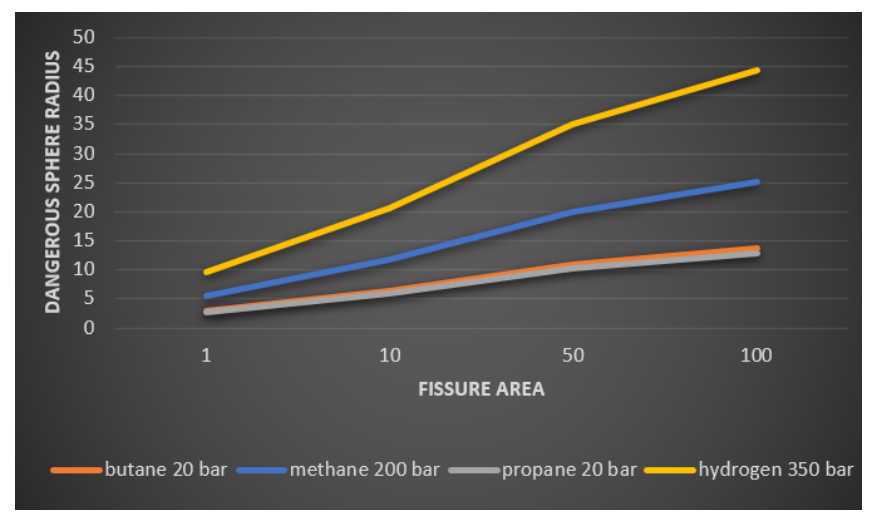

Fig. 9. Dangerous sphere radius correlation - fissure area dimension.

Figure 10 shows the radius of the sphere, in $[\mathrm{m}]$, for two different pressures for hydrogen in relation to the area of the crack $\left(1 \mathrm{~mm}^{2}, 10 \mathrm{~mm}^{2}, 50 \mathrm{~mm}^{2}\right.$ and $\left.100 \mathrm{~mm}^{2}\right)$.

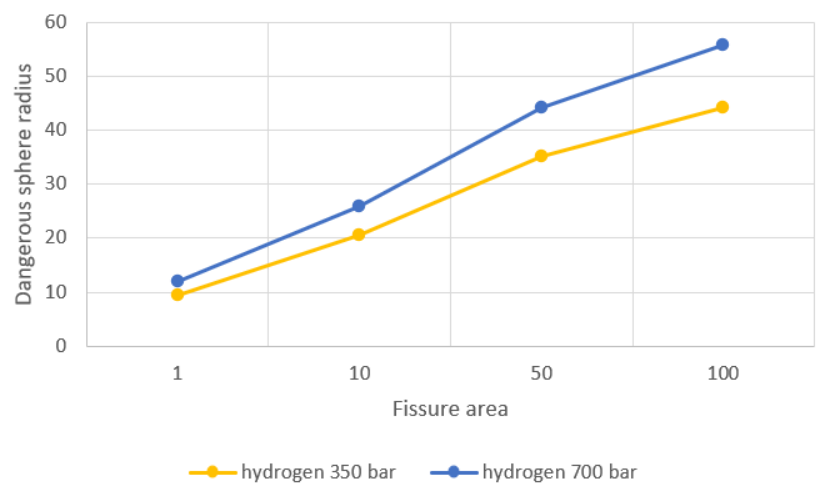

Fig. 10. Dangerous sphere radius correlation - fissure area dimension and pressure.

In the design, execution and maintenance of the hydrogen power stations of vehicles, account must be taken of the extent of the classified areas so that all necessary measures can be ensured to reduce the risk of explosion.

\section{Conclusion}

This paper highlights besides the benefits of using hydrogen as clean fuel source for cars and potential risks arising through its use. The presented application is very useful for determining the areas with increased risk of explosion so that even in the design, installation and use phase to take into account the restrictive conditions necessary not to harm primarily human safety and security but also environmental protection. These areas can occur during the production, storage and distribution of hydrogen. Thus, the minimum ignition energy of hydrogen, approximately $20 \mu \mathrm{J}$, must be taken into account, but also the influence of pressures on the zoning distances in order to use accordingly, in this classified area, equipment, corresponding components. 
In these areas, the risk of ignition of an explosive atmosphere may be reduced by the use of equipment, components and protective systems designed in accordance with the provisions of the technical standards for protection against explosion in force. Also, the explosion risk assessment takes into account the determinations and interpretations of combustible gas parameters. The main purpose of the explosion risk assessment is to increase the level of safety where an explosive atmosphere may occur.

As can be seen in almost all developed countries, the issue of addressing the sustainable development of hydrogen-based technologies is at the governmental level. In this regard, social partnerships have been created for consultations that include both economic agents and research entities or members of the academic community in order to find the optimal solutions for implementing a coherent program for the development of hydrogen-based technologies, as well as the need for a proper legislation which to facilitate the safely development of the infrastructure that is needed.

\section{References}

1. M.S. Nan, A. Sultan, et al, MATEC Web of Conferences 290, 11008, (2019)

2. A. Sultan, M.S. Nan, et al, MATEC Web of Conferences 305, 00070 (2020)

3. M. Gotz, J. Lefebvre et al., Renewable Energy J, 85 (2016) 1371-1390

4. ***, Guidance on hydrogen delivery systems for refuelling of motor vehicles, co-located with petrol fuelling stations (Energy Institute, London, 2017)

5. Directive 2014/34/EU (2014)

6. Standard SR EN 60079-0 (2013)

7. V.M. Pasculescu, E. Ghicioi, M.S. Morar, D. Pasculescu, M.C. Suvar, Quality - Access to

8. Success 20, 25-30 (2019)

9. V.M. Pasculescu, N.I. Vlasin, M.C. Suvar, C. Lupu, Environ Eng Manag J, 16 (6), 1323-1330 (2017)

10. V.M. Pasculescu, N.I. Vlasin, D. Florea, M.C., Suvar, Quality - Access to Success, 18, 97-102 (2019)

11. Ghicioi E., Vlasin N., Prodan M., Pasculescu V., Gabor D., Environ Eng Manag J, 16, 1290-1294, (2017)

12. Prodan M., Ghicioi E., Oancea D., Environ Eng Manag J, 13, 1409-1414, (2014)

13. Standard SR EN 60079-10-1 (2016) 